Tropical Journal of Pharmaceutical Research November 2015; 14 (11): 2009-2013

ISSN: $1596-5996$ (print); 1596-9827 (electronic)

(c) Pharmacotherapy Group, Faculty of Pharmacy, University of Benin, Benin City, 300001 Nigeria.

All rights reserved.

Available online at http://www.tjpr.org

Original Research Article

http://dx.doi.org/10.4314/tjpr.v14i11.9

\title{
Compositional Analysis and Antioxidant Activity of Volatile Components of Two Salvia spp
}

\author{
F Forouzin*, R Jamei and R Heidari \\ Department of Biology, Faculty of Science, Urmia University, West Azerbaijan, Iran
}

*For correspondence: Email: f_forouzin@yahoo.com, rjamei274@gmail.com, r.heidari@mail.urmia.ac.ir; Tel: 00989143457730

Received: 28 May 2015

Revised accepted: 3 October 2015

\begin{abstract}
Purpose: To identify and compare the composition of volatile components of two Salvia species, and also their free radical scavenging activity.

Method: The essential oil of two Salvia species was analyzed using gas chromatography-mass spectroscopy (GC-MS) techniques while their phenolic contents were analyzed by high performance liquid chromatography (HPLC). The in vitro antioxidant activity of the essential oils was evaluated by 1 , 1-diphenyl-2 picryl hydrazyl (DPPH) radical scavenging technique.

Results: Seven derivatives were identified for S. verticillata and four derivatives for S. suffruticosa. For both species, the main compounds were 1, 8-cineole (S. suffruticosa: $31.21 \%$ and S. verticillata: 38.26 $\%)$ and camphor (S. suffruticosa: $27.11 \%$ and S. verticillata: $22.98 \%$ ). The content of the phenolic compounds was: ascorbic acid (S. suffruticosa: $23.98 \%$ and S. verticillata: $33.53 \%$ ), p- hydroxyl benzoic acid (S. suffruticosa $11.50 \%$ and S. verticillata $3.83 \%$ ), vanilic acid (S. suffruticosa $5.86 \%$ and S. verticillata: $6.55 \%$ ), syringic acid (S. suffruticosa $6.29 \%$ ), ferulic acid (S. suffruticosa: $6.35 \%$ and S. verticillata $6.04 \%$ ) and sinapic acid (S. suffruticosa $6.26 \%$ and S. verticillata $4.93 \%$ ). DPPH radical scavenging ability was $0.548 \%$ for $S$. suffruticosa for S. suffruticosa and $0.558 \%$ for S. verticillata.

Conclusion: The results of this study demonstrated that these two species are rich in 1, 8-cineole, camphor and phenolic compounds. There is no significant difference between the radical scavenging activities of the two essential oils.
\end{abstract}

Keywords: S. verticillata, S. suffruticosa, essential oil, antioxidant activity, GC-MS, HPLC activity

Tropical Journal of Pharmaceutical Research is indexed by Science Citation Index (SciSearch), Scopus, International Pharmaceutical Abstract, Chemical Abstracts, Embase, Index Copernicus, EBSCO, African Index Medicus, JournalSeek, Journal Citation Reports/Science Edition, Directory of Open Access Journals (DOAJ), African Journal Online, Bioline International, Open-J-Gate and Pharmacy Abstracts

\section{INTRODUCTION}

Salvia is one of the largest genera of the Labiatae family. This genus includes nearly 700 species which are spread throughout the world [1]. Salvia species are aromatic plants, which are rich in essential oil [2]. In the flora of Iran, the genus is represented by about 58 species of which 17 are endemic [3]. The plants are naturally distributed in different parts of Iran and are called "Maryam goli" [4] in Persian. The name Salvia comes from the Latin word salvare, which means healer. The salvia species possess antibacterial, carminative, diuretic, hemostatic and spasmolytic activities and are used as herbal teas all around the world [5].

S. verticillata is a herbaceous perennial which can be found in a wide geographic area ranging from central Europe to western Asia [8,9]. The tiny lavender flowers grow tightly packed in whorls, with tiny lime-green and purple calyces $[7,8]$.

S. suffruticosa is a semi-shrub with branches from the base pinnate leaves that grow up to 50 
cm (20 inches) in height. It has bilabiate flowers, yellowish-white corolla, a galeiform upper lip, a tripartite lower lip, greenish calyx, tooth at the margins and thick stipulate glandules [10]. It is a well-known fact that the curative properties of many plants are due to their high contents of phenolics, which act as free radicals scavengers [10]. Thus, the objective of this study was to analyze the phenolic compounds present in the volatile of the studied plants.

The aim of this work is to compare volatile components of composition by GC-MS, to analyze the phenolic compounds by HPLC among two Salvia species and the testing of target compounds for their free radical scavenging activity by using DPPH in West Azerbaijan.

\section{EXPERIMENTAL}

\section{Plant material}

Aerial parts of $S$. verticillata (code no: 9539) and S. suffroticosa (code No: 9529) were collected at the beginning of flowering and their locations were marked by a Global Positioning System GPS system. This plant is a permanent herb which belongs to the Labiatae family and grows wild in some regions of Iran, including West Azerbaijan Province. The Salvia specimens were authenticated and stored in the herbarium of the West Azerbaijani Agricultural Research Center (Table 1).

\section{Extraction of volatile components}

One hundred grams portions of each air-dried samples was ground in a Waring blender and then the essential oils were extracted by hydrodistillation in a Clevenger apparatus for $120 \mathrm{~min}$. The oils were filtered over anhydrous Sodium sulphate to remove traces of moisture and stored in closed sterilized glass vials at $+4{ }^{\circ} \mathrm{C}$ in the dark until being analyzed and screened [11].

\section{Gas chromatography-mass spectrometry}

Analysis was performed on an Agilent 5973 gas chromatograph equipped with an ion-trap mass spectrometer detector (Varian Saturn 2100), using a ZB-5 (5 \% of phenyl- dimethylpolysiloxane), fused-silica capillary column (30 m x $0.25 \mathrm{~mm}$ i.d., $0.25 \mu \mathrm{m}$ film thicknesses). Helium was used as a carrier gas. The injection volume was $1 \mu \mathrm{L}$. The column temperature was $120^{\circ} \mathrm{C}$, with a $5 \mathrm{~min}$ initial hold and then it was increased to $260{ }^{\circ} \mathrm{C}$ at $10^{\circ} \mathrm{C} / \mathrm{min}$ rate. The injector and detector temperatures were 250 and $200{ }^{\circ} \mathrm{C}$, respectively and manifold at $70^{\circ} \mathrm{C}$ with line transfer at $240{ }^{\circ} \mathrm{C}$. The capillary column was coupled to a mass selective detector; the ionization energy voltage was 70 $\mathrm{eV}$, electron multiplier voltage was $3000 \mathrm{v}$ and ion resource temperature $200{ }^{\circ} \mathrm{C}$. Mass spectra were scanned in the range of $30-300$ amu [12].

\section{HPLC analysis}

A $20 \mu \mathrm{L}$ aliquot of the extracted solution was separated using a HPLC Knauer system equipped with UV-Vis detector and a Eurospher $100-5 \mathrm{C}-18$ column $(25 \mathrm{~cm} \times 4.6 \mathrm{~mm} ; 5 \mu \mathrm{m})$. The mobile phase consisted of HPLC grade water with $2 \%$ acetic acid (A) and acetonitrile (B). Solvent gradient was used as follows: from 0 to 5 min isocratic $85 \%$ A flow, from 5 to $19 \mathrm{~min}$ (14 min) a linear gradient of $85 \%$ A to $100 \%$ B. After termination of the cycle, $15 \mathrm{~min}$ of column equilibration (85\% A) were allowed prior next injection. Phenolic compounds were detected at a wavelength of $280 \mathrm{~nm}$ and identified by comparing their relative retention times and UV spectra with authentic compounds; they were detected using an external standard method [14].

\section{Evaluation of antioxidant activity}

The measurement of DPPH radical scavenging activity was carried out according to the method of Barros et al [15]. A total of $10 \mu \mathrm{L}$ of the essential oil of $S$. suffruticosa and $S$. verticillata was added to $2 \mathrm{~mL}$ of methalonic DPPH (0.0023 $\mathrm{mol} / \mathrm{L})$ solution. The mixture was incubated in room temperature for $1 \mathrm{~h}$ before the change in absorbance at $517 \mathrm{~nm}$ was measured. The radical scavenging activity (D) was calculated as in Eq 1:

$\left(D(\%)=\left\{\left(A_{0}-A_{1}\right) / A_{0}\right\} \times 100\right.$

where $A_{0}$ is the absorbance of the DPPH solution and $A_{1}$ is the absorbance of the sample.

Table 1: Geographic sampling location (UTM system) of the plant species

\begin{tabular}{lcccc}
\hline Salvia species & UTM system & Altitude $(\mathbf{m})$ & Collection date & Voucher no. \\
\hline S. suffruticosa & 38 S 496689 & 1657 & 4 June 2013 & 9539 \\
S. verticillata & 4209523 & & & 7 June 2013 \\
S S 0570079 & 4129194 & 1438 & & 9529 \\
\hline
\end{tabular}




\section{Data analysis}

Constituents were identified by GC-MS by comparison of their Kovats retention indices (RI) and also by comparison of the constituents' mass spectra with those of the Wiley libraries using NIST ver. 02 software [16]. For antioxidant activity, all data represent an average of three replicates. Mean values and standard deviation (SD, $n=3$ ) were calculated from the results. Comparison between groups was performed by one-way ANOVA. $P<0.05$ was considered statistically significant.

\section{RESULTS}

The essential oils of two Salvia species were extracted by hydro-distillation in a Clevenger apparatus and analyzed by GC - MS. Seven compounds were determined for $S$. verticillata with total essential oil content of $71.27 \%$; and 4 compounds were determined for $S$. suffruticosa with total essential oil content of $61.11 \%$. In $S$. suffruticosa, the main compounds were 1, 8cineole $(31.21 \%)$, camphor (27.11\%), dimethyl sulfone $(13.17 \%)$ and bornylacetate $(8.8 \%)$. In $S$. verticillata, the main compounds were 1 , 8cineole $(38.26 \%)$, and camphor $(22.98 \%)$. Other compounds with low concentrations were bicycloheptan (5.52\%), cyclohexane (1.67\%), apinene $(1.77 \%)$, camphene $(0.54 \%)$ and borneol (2.29 \%) (Table 2).

As the result, there was no significant difference between radical scavenging ability of $S$. suffruticosa and S. verticillata.

The concentrations of phenolic compounds in the Salvia samples are reported in Table 3.

Table 2: Essential oil composition of $S$. suffroticosa and S. verticillata

\begin{tabular}{lccc}
\hline Compounds & RI & S. suffroticosa & S. verticillata \\
\hline 1,8-cineole & 1059 & 31.21 & 38.26 \\
camphor & 1121 & 27.11 & 22.98 \\
bornyl acetate & 1277 & 8.81 & - \\
dimethyl sulfone & 727 & 13.17 & - \\
geranyl acetate & 1352 & - & - \\
a- Pinene & 948 & - & 1.77 \\
camphene & 943 & - & 0.54 \\
borneol & 1167 & - & 2.29 \\
bicycloheptan & 1581 & - & 5.52 \\
cyclohexane & 719 & - & 1.67 \\
\hline
\end{tabular}

$R I=$ Retention index

Table 3: Content of phenolic compounds in Salvia species

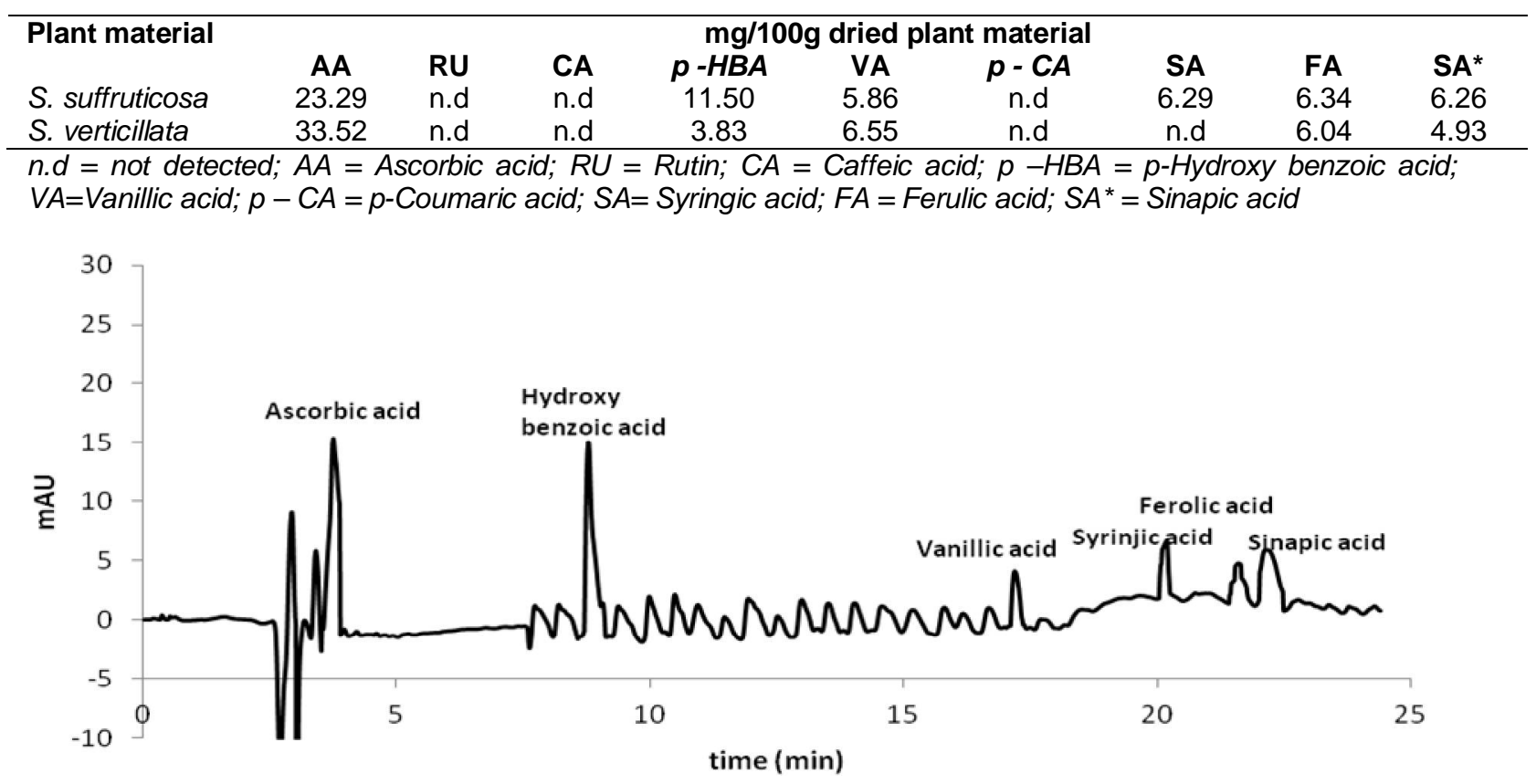

Figure 1: Chromatogram of identified phenolics compounds in S. suffruticosa 


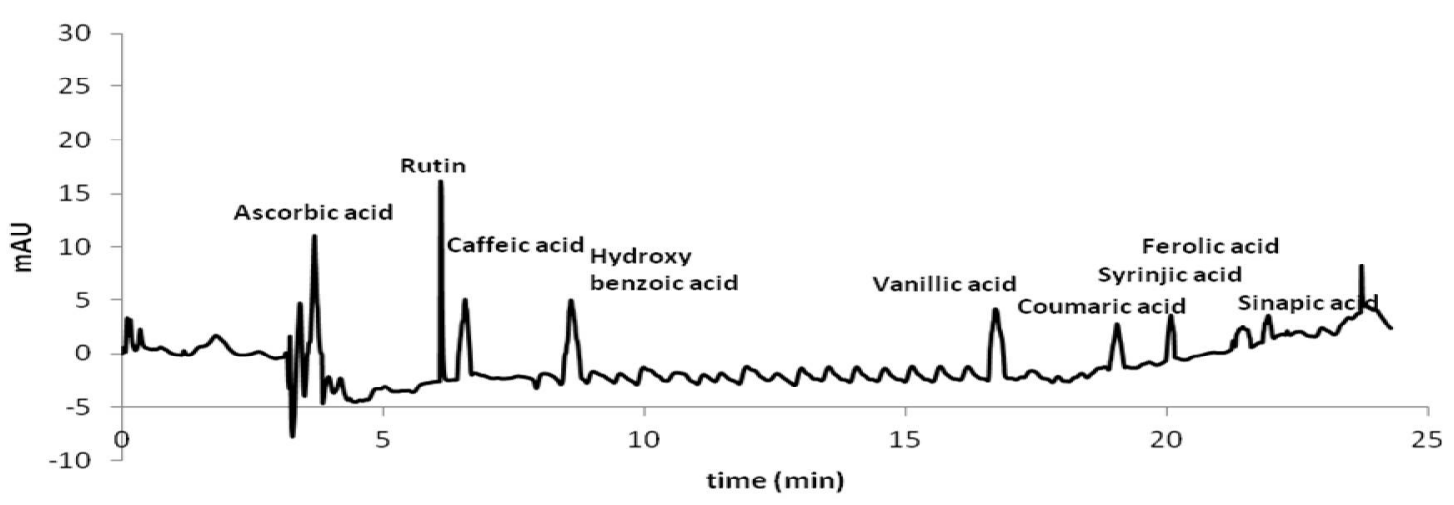

Figure 2: The chromatogram of identified phenolics compounds in S. suffruticosa

The DPPH radical scavenging activity of $S$. suffruticosa and $S$. verticillata was $0.548 \pm 0.026$ and $0.558 \pm 0.064$, respectively.

\section{DISCUSSION}

Each individual essential oil was composed of several dozen substances. However, usually a single compound is responsible for its flavor and pharmacological activity. The percentage of each individual constituent in the essential oil is variable and it depends on genetics (chemical variability) and environmental factors (climate, insolation, altitude) [17]. Qualitative and quantitative differences in essential oil composition can also relate to its extraction procedure [17].

Nasermoadeli et al found that e-caryophyellene, $\alpha$-gurjunene, germacrene- $d, \alpha$ - humulene, $\beta$ phellandrene, $\beta$-pinene and bicyclogermacrene are the main components of wild $S$. verticillata [18].

Sefidkon and Khajavi found $\beta$-caryophyllene, $\gamma$ murolene, limonene and $\alpha$-humulene as the major constituents of $S$. verticillata oil. Most of the compounds that were identified in essential oil of $S$. verticillata were present in other Salvia species but; in contrast to the other studies, no caryophyllene and $\alpha$-humulene were detected in their sample [19].

Norouzi-Arasi et al found 30 components in the essential oil of $S$. suffruticosa, of which the main components were camphor (48.5\%), 1, 8-cineole (18.6\%) and camphene (7.9\%) [20]. As stated previously, in our $S$. suffruticosa samples, the main compounds were 1, 8-cineole (31.21\%), camphor (27.11\%), dimethyl sulfone (13.17\%) and bornyl acetate (8.81\%).

These two species possess antioxidant potential. Extensive studies have been carried out on the antioxidant activity of many species of Salvia.
They demonstrated that this family species had strong antioxidant capacity. Some authors have demonstrated a linear correlation between the content of total phenolic compounds and their antioxidant capacity $[21,22]$.

Many papers have suggested the identified components presented here as the major derivatives of Salvia species [23,24]. It is obvious that these two species is valuable species in terms of biologically active principles content. 1,8-cineole, camphor, ascorbic acid, p-hydroxy benzoic acid, vanilic acid, ferrolic acid and sinapic acid were found in two species are chemical mediators in biochemical interactions among other plants and this could suggest models for lead compounds in the development of some products such as drugs and pesticides [25].

\section{CONCLUSION}

S. verticillata has higher total essential oil content than $S$. suffruticosa. S. verticillata is rich in 1,8cineole while $S$. suffruticosa is rich in camphor. Both species have approximately the same level of DPPH radical scavenging ability. The essential oils plants, because they are rich phenolic acids, are potentially a good source of natural antioxidants.

\section{ACKNOWLEDGEMENT}

The authors wish to thank the taxonomist, Mrs Mozhgan Larti of Herbarium of West Azerbaijan Agriculture and Natural Resources Researches Center, for assistance with the authentication of the plant materials.

\section{REFERENCES}

1. Ewans WC, Trease GE. Trease and Ewans Pharmagonosy. Bailliere and Tindolli. 1996; pp 498504.

Trop J Pharm Res, November 2015; 14(11): 2012 
2. Baratta MT, Dorman HJ, Deans SG, Figueiredo AC, Barroso JC, Ruberto G. Antimicrobial and antioxidant properties of some commercial essential oils. Flavour Frag. J. 1988; 13(4): 235-244.

3. Rechinger KH. Flora Iranica. Germany 1982; pp 403-476.

4. Mozaffarian VA. Dictionary of Iranian plant names, Tehran. 3d ed, Iran. 1996; 207.

5. Ulubelen A, Topcu G. Chemical and biological investigations of Salvia species growing in Turkey. Studies in Natural Product Chemistry. 1998; 20: 659718.

6. Gharaman A. Flora colored Iran. Forest and range and research organization. Tehran. 1st ed. 2003; $p 24$.

7. Zolfaghari-far $M$, Ardastani $S$, Farsam $H$, Sori $E$. Antioxidant activity of methanolic extract and some fractions of Salvia verticillata using three different methods. Med Plant J. 2007; 21: 21-41.

8. Goren AC, Kilic T, Dirmenci T, Bilsel G. Chemotaxonomic evaluation of Turkish species of Salvia: fatty acid composition of seeds oils. Biochem. Syst. Ecol. 2006; 34:160-164.

9. Movsesyan SD, Ayrumyan, KA. Red data book of Armenian SSR. 1988. P.103-114.

10. Baytop T. Therapy with medicinal plants in Turkey (past and present). Nobel Tip Kitaberleri. $2 d$ ed. 1999; $p$ 142.

11. Gulfraz M, Mehmood S, Minhas N, Jabeen N, Kausar R, Jabeen $K$, Arshad G. Composition and antimicrobial properties of essential oil of Foeniculum vulgare. Afr. J. Biotechnol. 2008; 7(24): 4364-4368.

12. Duarte Coutinho I, Lima Cardoso CA, Re-Poppi N, Mestriner Melo A, Carmo Vieira MD, Kika Honda M, Gomes Coelho R. Gas chromatography-mass spectrometry (GC-MS) and evaluation of antioxidant and antimicrobial activities of essential oil of Campomanesia adamantium (Cambess.) O. Berg (Guavira). BJPS. 2009; 45(2): 769.

13. Hertog M.G.L, Hollman P.C.H, Venema D.P. Optimization of a quantitative HPLC determination of potentially anticarcinogenic flavonoids in vegetables and fruits. J. Agric. Food Chem. 1992; 40: 1591-1598.

14. Akbari V, Jamei $R$, Heidari $R$, Jahanban Sfahlan $A$. Antiradical activity of different parts of Walnut (Juglans regia L.) fruit as a function of genotype. Food Chem. 2012; 135: 2404-2410.
15. Barros L, Baptista P, Ferreira ICFR. Effect of Lactarius piperatus fruiting body maturity stage on antioxidant activity measured by several biochemical assays. Food Chem Toxicol. 2007; 45: 1731-1737.

16. Thenmozhi S, Rajan S. GC-MS analysis of bioactive components in Psidium guajava leaves. J. Pharmacogn Phytochem. 2015; 3(5): 162-166.

17. Farhat GN, Affara NI, Gali-Muhtasib HU. Seasonal changes in the composition of the essential oil extract of East Mediterranean sage (Salvia libanotica) and its toxicity in mice. Toxicon. 2001; 39(10): 1601-1605.

18. Richer J, Schellenberg $I$. Comparison of different extraction methods for the determination of essential oil related compounds of aromatic plants and optimization of solid-phase micro extraction/gas chromatography. Anal. Bioanal. Chem. 2007; 387(6): 2207-17.

19. Nasermoadeli S, Rowshan V, Abotalebi A, Nasermoadeli L, Charkhchian M. Comparison of Salvia verticillata essential oil components in wild and cultivated population. Anal. Bioanal. Res. 2013; 4(5): 252-525.

20. Sefidkon F, Khajavi MS. Chemical composition of the essential oils of two Salvia species from Iran: Salvia verticillata $L$. and Salvia santolinifolia Boiss. Flavour Frag. J. 1999; 14: 77-78.

21. Norouzi-Arasi $H$, Yavari I, Chalabian $F$, Baghaii $P$, Kiarostami V, Nasrabadi M, Aminkhani A. Volatile constituents and antimicrobial activities of Salvia suffruticosa Montbr. and Auch. Ex Benth. from Iran. Flavour Frag. J. 2005; 20(6):633-636.

22. Djeridane $A$, Yousefi $M$, Nadjemi B, Boutassouna $D$, Stocker $P$, Vidal N. Antioxidant activity of some Algerian medicinal plants extracts containing phenolic compounds. Food Chem. 2006; 97: 654-660.

23. Katsube T, Tabata H, Ohta Y, Yamasaki Y, Anuurad E, Shiwaku K. Screening for antioxidant activity in edible plant products: comparison of low-density lipoprotein oxidation assay, $D P P H$, radical scavenging assay and Folin- Ciocalteu assay. J. Agric. Food Chem. 2004; 52: 2391-2396.

24. Sajadi SE, Shahpiri Z. Chemical composition of Salvia limbata C. A. Mey. Daru J. 2004; 12(3): 94-97.

25. Duke SO, Dayan FE, Romagni JG, Rimando A. Natural products as sources of herbicides: current status and future trends. Weed Res. 2000; 40: 99-111. 